\title{
Design Of Array and Circular Polarization Microstrip Antenna For LTE Communication
}

\author{
Syah Alam $^{1, *}$, Eddy Wijanto ${ }^{2 . *}$, Budi Harsono ${ }^{2}$, Fidelia Samandatu ${ }^{2}$, Markus Upa ${ }^{2}$, Indra \\ Surjati $^{3}$ \\ ${ }^{1}$ Departemen of Electrical Engineering, Universitas 17 Agustus 1945 Jakarta, DKI Jakarta, Indonesia \\ ${ }^{2}$ Department of Electrical Engineering, Universitas Kristen Krida Wacana, DKI Jakarta, Indonesia \\ ${ }^{3}$ Graduate Programe of Electrical Engineering, Universitas Trisakti, DKI Jakarta, Indonesia
}

\begin{abstract}
This paper proposes a high gain microstrip antenna with circular polarization for LTE applications at a working frequency of 2300 MHz. Gain of antenna is optimized by using an array method with 4 elements arranged in plannar using feed line of $50 \mathrm{Ohm}, 100 \mathrm{Ohm}$ and $70.7 \mathrm{Ohm}$. The proposed antenna designed using FR-4 substrate with $(\mathrm{Er})$ $=4.3$, substrate thickness $(\mathrm{h})$ of $1.6 \mathrm{~mm}$ and loss tangent $(\tan \delta)$ of 0.0265 . Gain of antenna can be optimized by increasing the number of elements in the array of the antenna. Circular polarization can be obtained by cutting the edge of a rectangular patch antenna with an angle of $45^{\circ}$. From the simulation results obtained reflection coefficient value of $-20.02 \mathrm{~dB}$ and VSWR of 1.22 at the working frequency of $2300 \mathrm{MHz}$. The gain of proposed microstrip antenna is $10.56 \mathrm{~dB}$ with an impedance bandwidth value of $714 \mathrm{MHz}(1925-2639 \mathrm{MHz})$. The proposed antenna obtained a circular polarization with axial ratio of $1.745 \mathrm{~dB}$ at working frequency of $2300 \mathrm{MHz}$. Array method with four elements increased the gain of antena until $45.07 \%$ compared to the single element antenna.
\end{abstract}

\section{Introduction}

At present time, the development of mobile telecommunication technology and communication system is growing very rapidly, especially the development in the mobile and wireless telecommunications. The society needs for communication and high transfer data rates are getting higher along with the entry of 4G Long Term Evolution technology. The stability of the connection and the speed of data transfer becomes very important to make the telecom provider optimize the network in order to meet customer needsthere are several telecommunication systems that have been developed, for example is DCS at frequency band (1710 MHz -1885 MHz), PCS (1907 MHz -1912.5MHz), UMTS (1920 $\mathrm{MHz}-2170 \mathrm{MHz}$ ), WLAN $2.4 \mathrm{GHz}$ and LTE $2.3 \mathrm{GHz}$ [1]. The band frequency of 2300 $\mathrm{MHz}-2400 \mathrm{MHz}$ is used for broadband communication system such as Long Term Evolution and Wireless Fidelity in accordance with the Regulation of the Minister of

\footnotetext{
*Corresponding author: alam_bizkit@yahoo.com
} 
Communication and Information of the Republic of Indonesia Number 28 / PER / M.KOMINFO / 09/2014 [2].

In modern telecommunication devices such as modem usually use an internal antenna that has a small gain so that the reception of signal is not optimal. To solve that problem can be used an external antenna but sometimes the dimension of external antenna is big enough so that it becomes ineffective in its application. In addition, the type of external antenna sold in the market also has a vertical polarization (dipole) while the transmitting antenna used in the BTS (Base Transmission Station) has a horizontal polarization causing a loss on the receiver side due to its cross polarization between the receiving antenna and the transmitter. To overcome this problem microstrip antennas can be developed with circular polarization to reduce the loss caused by cross polarization of the transmitting and receiving antennas. In addition, microstrip antennas has advantages such as small and compact dimensions so the application is more effective beside that microstrio antenna can delovoped to produce circular polarization. It provides both linear and circular polarization. However, microstrip antenna has disadvantages such as low level gain, narrow bandwidth, low efficiency, and low directivity [3]. The circular polarization (CP) is a special case of elliptical polarization and it is realized when antenna configuration excites two equal amplitude, time and space orthogonal resonant modes [4]. Polarization loss may result due to the misalignment in the signal and the receiving antenna. To solve this problem we can used microstrip antenna with circular polarization [5].

To obtain microstrip antenna that has a circular polarization can be used several methods such as fractal [6], truncated corner [7] and proximity coupling [8]. In this research, the truncated corner method is used by cutting the upper and lower edges of the rectangular shape antenna, the selection of this method is because the initial dimension of the designed microstrip antenna is rectangular so that the use of truncated method is much easier and more effective in designing, the truncated corner method also reduces the dimensions of the antenna into smaller ones resulting in a more compact dimension. Beside that to increase the gain of the antenna can be done by using array method [9-12]. In a previous study [13-15] obtained a circular polarization using the truncated corner method.

In this research, the microstrip antenna is designed using truncated corner method to produce axial ratio $\leq 3 \mathrm{~dB}$. After that, gain of the microstrip antenna can be optimized by using an array method using 4 elements. The selection of the trucanted corners method caused by the dimensions used in the initial design is rectangular which is easier and more effective in designing to produce circular polarization. The type of array used is the plannar array because it is more effective to optimizing the gain value of the antenna. The type of substrate used in the design of the antenna is FR-4 Epoxy with $(\mathrm{Er})=4.3$, substrate thickness $(\mathrm{h})$ of $1.6 \mathrm{~mm}$ and loss tangent $(\tan )$ of 0.0265 . The design and simulation process of the proposed antenna uses AWR Microwave Office.

\section{Design of Antenna}

Circular polarization microstrip antenna is designed using double layer substrate of FR4 Epoxy with relative permittivity (cr) of 4.3, substrate thickness (h) of $1.6 \mathrm{~mm}$ and loss tangent $(\tan \delta)$ of 0.0265 . The first stage is to design a rectangular antenna with microstrip line feeder of $50 \mathrm{Ohm}$ that works at working frequency of $2300 \mathrm{MHz}$ for LTE applications. To determine the dimensions of $\mathrm{W}$ and $\mathrm{L}$ of the initial design antenna we can use the equations below (1), (2), (3) and (4)[16]. The width dimension of the microstrip line feeder of $50 \mathrm{Ohm}(\mathrm{Wf})$ is obtained using equations (6) and (7)[17]. The design of the rectangular microstrip antenna can be seen in Figure 1. 


$$
\begin{array}{ll}
\mathrm{W} & =\frac{C}{2 f \sqrt{\frac{\varepsilon r+1}{2}}} \\
\mathrm{~L} & =\mathrm{L}_{\text {eff }}-2 \Delta \mathrm{L} \\
\mathrm{L}_{\text {eff }} & =\frac{C}{2 f \sqrt{\varepsilon_{\text {reff }}}} \\
\varepsilon_{\text {reff }} & =\frac{\varepsilon r+1}{2}+\frac{\varepsilon r-1}{2}\left[1+12 \frac{h}{W}\right]^{-\frac{1}{2}} \\
\mathrm{~B} & =\frac{60 \pi^{2}}{Z_{0} \sqrt{\varepsilon_{\text {eff }}}}
\end{array}
$$$$
W f=\frac{2 h}{\pi}\left\{B-1+\frac{\varepsilon_{r}-1}{2 \varepsilon_{r}}\left[\ln (B-1)+0.39-\frac{0.61}{\varepsilon_{r}}\right]\right\}
$$

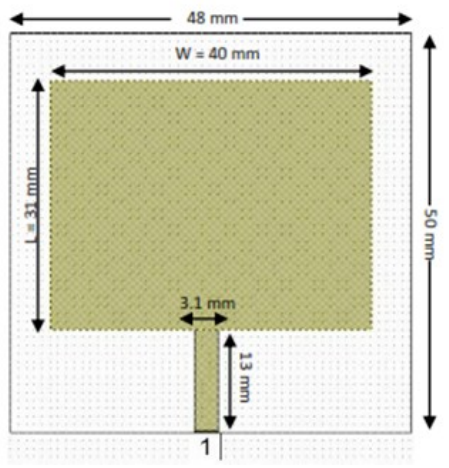

Fig.1 Design of Rectangular Microstrip Antenna

The second stage is to design truncated corner of microstrip antenna with cutting angle of $45^{\circ}$ at the diagonal position. The main purposes of cutting the patch side of an antenna is to produce a circular polarization with a $3 \mathrm{~dB}$ axial ratio. Circular polarization occurs due to interference with the current flowing in the patch affecting the polarization of the antenna. The dimensions of the cut width on the patch antenna can be determined using equation (7) [18]. The design of the truncated corner of microstrip antenna design can be seen in Figure 2.

$\Delta L=1 / 4 \times L$

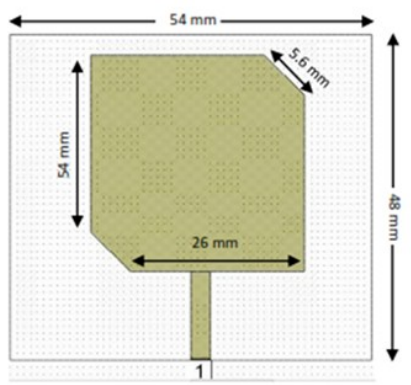

Fig.2 Design of Truncated Microstrip Antenna 
The final stage is designing the microstrip antenna using the array method to optimized the gain of antenna by using four patch with feed line of $Z_{1}=50 \mathrm{Ohm}, \mathrm{Z}_{2}=70.7 \mathrm{Ohm}$ and $\mathrm{Z}_{3}=100 \mathrm{Ohm}$. Dimension and width of feed line (Wf) of $50 \mathrm{Ohm}, 70.7 \mathrm{Ohm}$ and $100 \mathrm{Ohm}$ can be determined using formula (6) and (7) while to determine the distance between patches in the array method is given by (8) [19].

$\mathrm{d}=\frac{\lambda}{2}$

The design of truncated mirostrip antenna using array with 4 element can be seen in Figure 3.

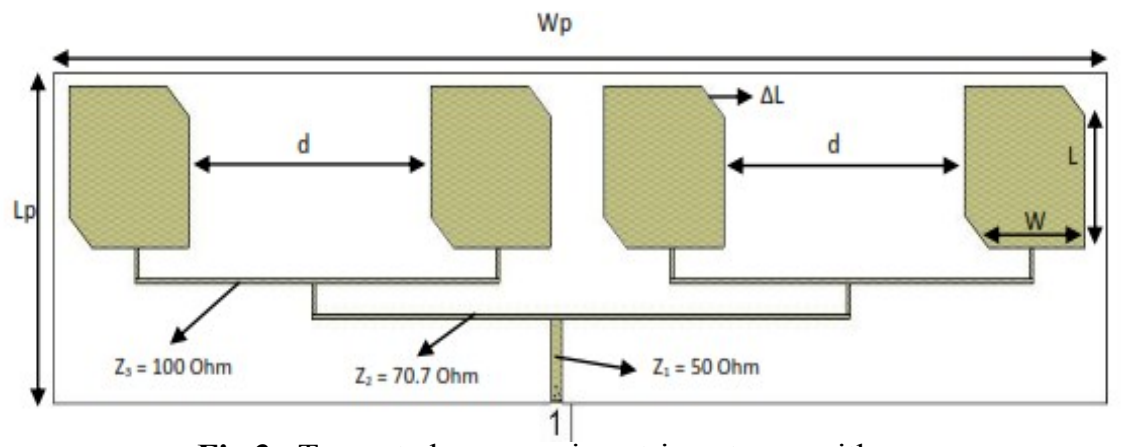

Fig 3. Truncated corner microstrip antenna with array

From Figure 3 above can be seen the dimension of array microstrip antenna with $\mathrm{W}=26$ $\mathrm{mm}, \mathrm{L}=26 \mathrm{~mm}, \mathrm{~d}=64 \mathrm{~mm}$ and $\Delta \mathrm{L}=5.6 \mathrm{~mm}$. The dimension of the enclosure is $\mathrm{Wp}=$ $280 \mathrm{~mm}$ and $\mathrm{Lp}=65 \mathrm{~mm}$ while the width of feeder channel $Z_{1}, Z_{2}$ and $Z_{3}$ are $3.1 \mathrm{~mm}, 1.6$ $\mathrm{mm}$ and $1 \mathrm{~mm}$.

\section{Result and Discussion}

After the design process, the next stage performs the simulation process of the design antenna using AWR Microwave Office. The observed parameters are reflection coefficient, VSWR, axial ratio and gain of the antenna. The simulation results of these parameters can be seen in the Figure 4, Figure 5, and Figure 6.

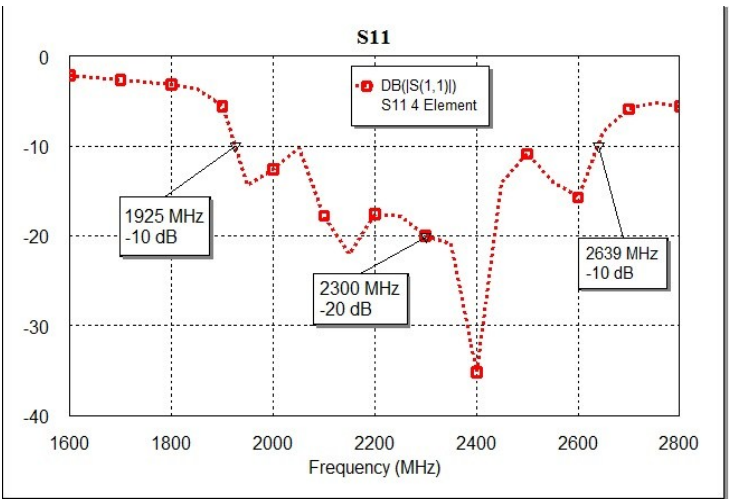

Fig 4. Simulation result of reflection coefficient 


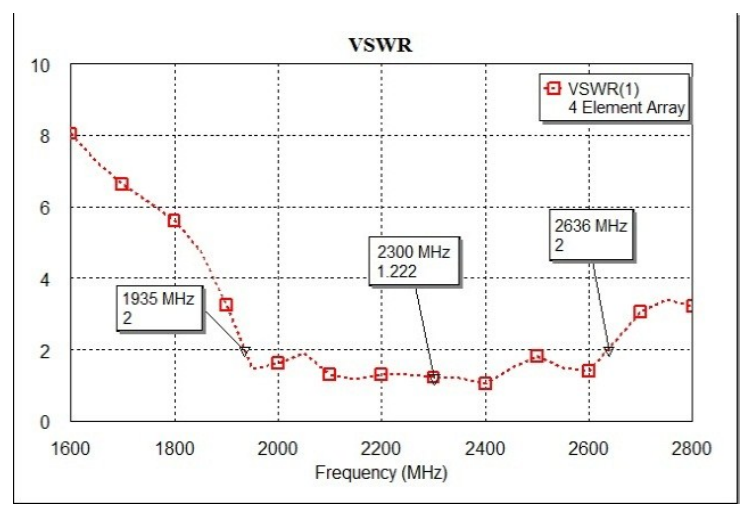

Fig 5. Simulation result of VSWR

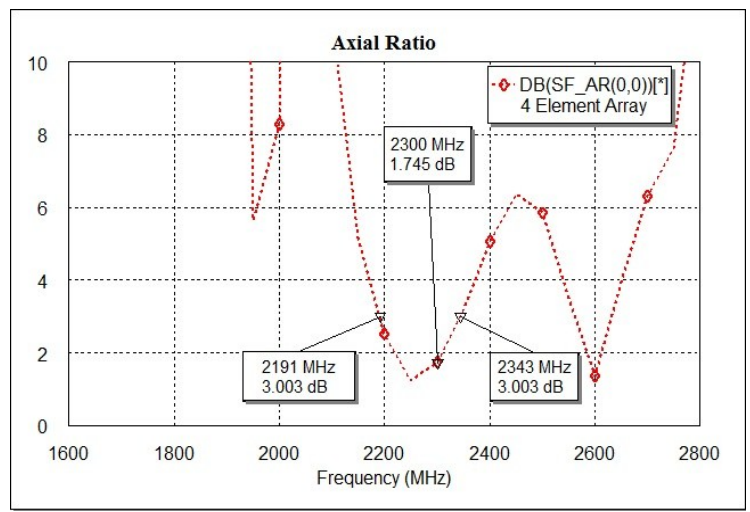

Fig 6. Simulation result of Axial Ratio

From Figure 4 and Figure 5 it can be seen that the proposed antenna has a reflection coefficient of $-20 \mathrm{~dB}$ and VSWR of 1.22 at a working frequency of $2300 \mathrm{MHz}$. This is in accordance with the minimum standards set for the reflection coefficient $\leq-10 \mathrm{~dB}$ and VSWR $\leq 2$ so it can be said that the antenna already has a good reflection coefficient and VSWR. The bandwidth obtained from the proposed antenna is $714 \mathrm{MHz}(1925-2639$ $\mathrm{MHz}$ ).

From Figure 6 it can be seen that the axial ratio obtained from the proposed antenna is $1.745 \mathrm{~dB}$ at a working frequency of $2300 \mathrm{MHz}$. This proves that the proposed antenna has a circular polarization with an axial ratio of $\leq 3 \mathrm{~dB}$ at a predetermined working frequency of $2300 \mathrm{MHz}$. The bandwidth of the axial ratio obtained from the proposed antenna is 152 $\mathrm{MHz}(2191-2343 \mathrm{MHz}$ ) The gain of antena can be optimized by increasing the number of elements in the array of the antenna. The simulation results of gain from optimization process of the proposed antenna are shown in Figure 7. 


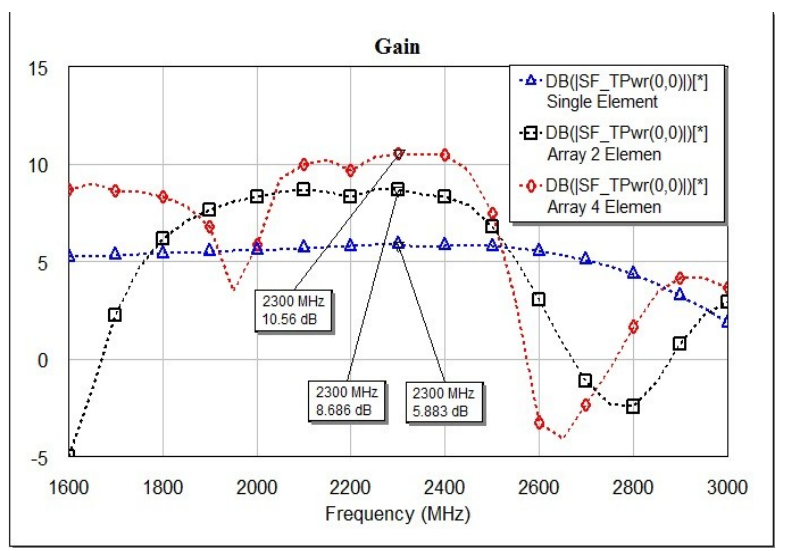

Fig 7. Simulation result of Gain

From Figure 7 it can be seen that the gain increase occurs as the number of elements increases. The gain obtained from the proposed antenna is $10.56 \mathrm{~dB}$ at a working frequency of $2300 \mathrm{MHz}$ using 4 elements. The comparison of the overall optimization process of gain on the proposed antenna can be seen in table 1 below.

Table 1. Comparison Gain of Microstrip Antenna

\begin{tabular}{|l|c|l|}
\hline \multirow{2}{*}{ Condition } & \multicolumn{2}{c|}{ Parameter } \\
\cline { 2 - 3 } & Gain & Frequency \\
\hline Single Element & $5.883 \mathrm{~dB}$ & $2300 \mathrm{MHz}$ \\
\hline Array 2 Element & $8.685 \mathrm{~dB}$ & $2300 \mathrm{MHz}$ \\
\hline Array 4 Element & $10.56 \mathrm{~dB}$ & $2300 \mathrm{MHz}$ \\
\hline
\end{tabular}

From table 1 above it can be seen that the gain enhancement of the array antenna is directly proportional to the number of elements. The gain obtained from the single element antenna is $5.883 \mathrm{~dB}$, while in the 2 element array it increases to $8.685 \mathrm{~dB}$ and in the 4 element array increases to $10.56 \mathrm{~dB}$ at working frequency of $2300 \mathrm{MHz}$. This result proves that the array method on the proposed antenna successfully increases the gain value up to $45.07 \%$ compared to the single element antenna. The result of the simulation of the radiation pattern on the proposed antenna can be seen in Figure 6 below. 


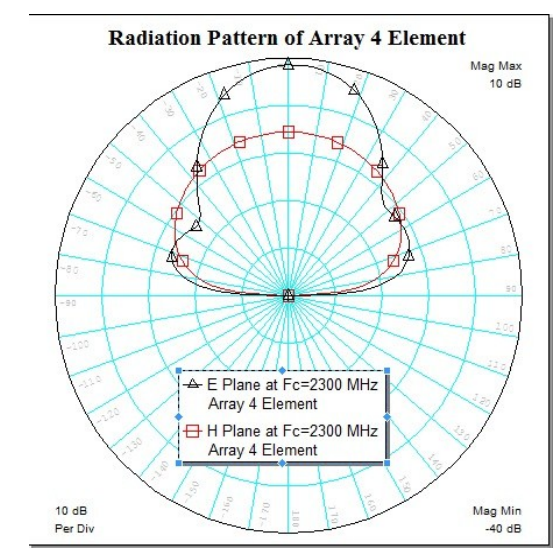

Fig 8. Radiation Pattern of Proposed Antenna

From Figure 8 it can be seen that the radiation pattern generated from the proposed antenna is broadside with the best transmit angle at $0^{0}$. The effect of using arrays is produces a side lobe on the radiation pattern of the proposed antenna.

From the overall results it can be seen that the truncated corner method succeeded in producing circular polarization of antennas with axial ratio $\leq 3 \mathrm{~dB}$. In addition, the array method with 4 elements succeeded in increasing gain of antenna from $5.883 \mathrm{~dB}$ until 10.56 $\mathrm{dB}$, increasing $47.80 \%$ compared to single element antenna.

\section{Conclusion}

A new design of high gain and circular polarization of microstrip antenna is eventually well proposed. The circular polarization is obtained by cutting the edges of the patch antenna while to increase the gain value is obtained by increasing the number of elements on the antenna. From the simulation results obtained the reflection coefficient of $-20 \mathrm{~dB}$, VSWR of 1.22 and axial ratio of $1.72 \mathrm{~dB}$ at $2300 \mathrm{MHz}$ working frequency. The gain of the proposed antenna is $10.56 \mathrm{~dB}$ or an increase of $40.78 \%$ compared to the single elemet antenna.

The authors wish to express their gratitude to the LPPM of Universitas Kristen Krida Wacana for their support through Grant of Internal Researh fiscal of year 2018.

\section{References}

1. DITJEN POSTEL, "Structuring the Radio Frequency-Based Service Broadband Wireless Access". Jakarta, 2006.

2. Ministry of Communication and Information of the Republic of Indonesia, PERMENKOMINFO No.28 / PER / M.KOMINFO / 09/2014 "Establishment of Radio Frequency Band For Customers Wireless Broadband Service (Wireless Broadcast) At $2.3 \mathrm{GHz}$ Frequency Band". Jakarta, 2014.

3. Dalvi, S., Jagtap, S., Yadav, V., \& Gupta, R. K. (2016, January). High gain wideband $2 \times 2$ microstrip array antenna using RIS and Fabry Perot Cavity resonator. In Microelectronics, Computing and Communications (MicroCom), 2016 International Conference on (pp. 1-6). IEEE.

4. İmeci, T., \& Saral, A. (2010). Corners Truncated Microstrip Patch Antenna. 26th Annual Review of Progress in Applied Computational Electromagnetics. 
5. Alam, S., Surjati, I., \& Ningsih, Y. K. (2017, November). Patch modification and slot arrangement of microstrip antenna for improving the axial ratio. In Broadband Communication, Wireless Sensors and Powering (BCWSP), 2017 International Conference on (pp. 1-5). IEEE.

6. Reddy, V. V., \& Sarma, N. V. S. N. (2014). Compact circularly polarized asymmetrical fractal boundary microstrip antenna for wireless applications. IEEE Antennas and Wireless Propagation Letters, 13, 118-121.

7. Rahman, M. A., Nishiyama, E., \& Toyoda, I. (2017). A frequency diversity reconfigurable antenna with circular polarization switching capability. In Antennas and Propagation \& USNC/URSI National Radio Science Meeting, IEEE International Symposium on (hal. 1367-1368). IEEE.

8. Chen, S. J., Fumeaux, C., Monnai, Y., \& Withayachumnankul, W. (2017). Dual Circularly Polarized Series-Fed Microstrip Patch Array With Coplanar Proximity Coupling. IEEE Antennas and Wireless Propagation Letters, 16, 1500-1503.

9. Gupta, A., Choudhary, V., \& Tripathy, M. R. (2018). An M-Shaped Microstrip Antenna Array for WLAN, WiMAX and Radar Applications. In Progress in Intelligent Computing Techniques: Theory, Practice, and Applications (pp. 509-515). Springer, Singapore.

10. Amjadi, S. M., \& Sarabandi, K. (2017). A Low-Profile, High-Gain, and Full-Band SubArray of Cavity-Backed Slot Antenna. IEEE Transactions on Antennas and Propagation, 65(7), 3456-3464.

11. Faroqi, A., Zaelani, F., Kariadinata, R., \& Ramdhani, M. A. (2018, January). On The Design of Array Microstrip Antenna with S-Band Frequency for Radar Communication. In IOP Conference Series: Materials Science and Engineering (Vol. 288, No. 1, p. 012006). IOP Publishing.

12. S. Alam, I. G. N. Y. Wibisana and I. Surjati, "Miniaturization of array microstrip antenna using peripheral slits for wireless fidelity communication," 2017 15th International Conference on Quality in Research (QiR) : International Symposium on Electrical and Computer Engineering, Nusa Dua, 2017, pp. 91-95.

13. Nestoros, M., Christou, M. A., \& Polycarpou, A. C. (2017). Design of Wideband, Circularly Polarized Patch Antennas for RFID Applications in the FCC/ETSI UHF Bands. Progress In Electromagnetics Research, 78, 115-127.

14. Lai, H. W., Xue, D., Wong, H., So, K. K., \& Zhang, X. Y. (2017). Broadband circularly polarized patch antenna arrays with multiple-layers structure. IEEE Antennas and Wireless Propagation Letters, 16, 525-528.

15. Tang, M. C., Chen, X., Li, M., \& Ziolkowski, R. W. (2017). A Bandwidth-Enhanced, Compact, Single-Feed, Low-Profile, Multilayered, Circularly Polarized Patch Antenna. IEEE Antennas and Wireless Propagation Letters, 16, 2258-2261.

16. Wang, M. S., Zhu, X., Guo, Y., \& Wu, W. (2018). Compact Circularly Polarized Patch Antenna With Wide Axial Ratio Beamwidth. IEEE Antennas and Wireless Propagation Letters.

17. Alam, S., Surjati, I., Ferawan, A., \& Firmansyah, T. (2018). Design and Realization of Compact Microstrip Antenna Using Fractal Sierpenski Carpet For Wireless Fidelity Application. Indonesian Journal of Electrical Engineering and Informatics (IJEEI), 6(1), 70-78.

18. Chen, W. S., Wu, C. K., \& Wong, K. L. (2001). Novel compact circularly polarized square microstrip antenna. IEEE Transactions on Antennas and propagation, 49(3), 340-342.

19. Surjati, Indra. "Microstrip Antenna: Concepts and Applications". 2010. Jakarta: Universitas Trisakti 